\title{
O ESTADO DA ARTE DA PRESERVAÇÃO DE ACERVOS AUDIOVISUAIS
}

Júlio César Silveira Tauil (Graduando de Biblioteconomia e Ciência da Informação -

UFSCar)

Prof. Ana Carolina Simionato (Orientadora)

\section{RESUMO}

O audiovisual é um patrimônio cultural de imprescindível relevância. As especificidades que envolvem a documentação audiovisual se diferenciam da documentação do tipo textual em vários aspectos, como por exemplo, na pluralidade dos diversos tipos de conteúdos e formas. A digitalização deste material é uma ferramenta de vital importância para a sua sobrevivência. Porém somente digitalizar o material não assegura a eficácia de sua preservação, é imprescindível conservar o acervo analógico, e os dispositivos tecnológicos responsáveis pela criação e execução dos suportes, neste caso se faz necessário que as unidades de informação tenham em suas equipes profissionais. Dessa forma, o audiovisual como outros acervos especiais, necessita de políticas de preservação e com formas teórico-metodológicas adequadas, assim, o objetivo da pesquisa ainda em desenvolvimento, é analisar novas perspectivas transdisciplinares relacionadas a preservação do acervo audiovisual, a partir do método estado da arte. Espera-se a partir dos estudos, de carácter exploratório e teórico acerca do tema, possa oferecer subsídios eficazes para políticas de preservação de audiovisuais.

Palavras-chave: Políticas de preservação, Acervos audiovisuais, Preservação.

\section{INTRODUÇÃO}

O presente trabalho pretende levantar problemáticas a respeito dos acervos audiovisuais, o acervo é a principal fonte de informação cuja finalidade está em conceber sabedoria e desenvolvimento cultural (INNARELLI, 2011). No geral, existem muitas dúvidas a respeito da conceituação do suporte audiovisual, e no âmbito da Ciência da Informação o acervo audiovisual não é contemplado por uma delimitação concisa nas três áreas desta ciência (Arquivologia, Biblioteconomia e Museologia). Sobre esta problemática a pesquisadora Smit (1993) utiliza o termo no man's land, numa tradução aproximada para o português o termo significa 'terra de ninguém', este contexto indica um forte indício de falta de cooperação e padronização em relação à organização e manutenção destes acervos.

Contudo, as dúvidas e a falta de padronização que norteiam o universo dos acervos audiovisuais não é somente um problema interdisciplinar, é também transdisciplinar, pois a preservação e disseminação das informações contidas em acervos audiovisuais envolvem diversas áreas do conhecimento, para variadas finalidades. Quando se trata do futuro dos acervos audiovisuais entra em jogo não só um precioso círculo de informação e conhecimento, também se trata do registro de parte da memória da humanidade. Em 2005, mais precisamente no dia 27 de outubro, a UNESCO (Organização das Nações Unidas para a Educação, Ciência e Cultura) em parceria com a CCAAA (Conselho de Coordenação das Associações de Arquivos 


\section{SEMINÁRIO DE PESQUISA EM CIÊNCIAS HUMANAS - SEPECH \\ Humanidades, Estado e desafios didático-científicos \\ Londrina, 27 a 29 de julho de 2016}

Audiovisuais) institucionalizou esta data como sendo o dia Mundial do Patrimônio Audiovisual (SOTERO, 2013, não paginado).

Diante dos conflitos interdisciplinares e transdisciplinares que giram em torno dos acervos audiovisuais, pretende-se abordar neste estudo vários aspectos da natureza que procuram definir e conceituar o suporte audiovisual, tanto na esfera analógica como na digital, pois o suporte audiovisual ainda é caracterizado de formas divergentes, portanto a definição e conceituação por si só oferece uma pluralidade razoavelmente complexa.

Outra abordagem de suma importância no presente estudo será verificada por meio de questões que circundam as estratégias de preservação adotadas pelas mais variadas Unidades de Informação e pelos diversos órgãos nacionais e internacionais. É de fundamental importância ressaltar que em todo processo desta presente pesquisa, o projeto focará em suportes e/ou acervos analógicos e digitais. A obsolescência de ferramentas intermediárias, responsáveis pela execução dos suportes audiovisuais, a do próprio material audiovisual, será devidamente abordada dentro da esfera das estratégias de preservação. Compreender as tecnologias e os processos que abarcam a preservação é considerado de extrema importância, pois em algum momento existiu a crença que o material digital não possuía problemas interligados ao acondicionamento, degradação do suporte, obsolescência, falta de segurança e espaço de armazenamento, entretanto o convívio cotidiano sinalizou que os objetos intermediários (como os HD's, por exemplo) não resolvem por conta própria esta gama de problemas, na realidade, engloba novos problemas que necessitam da intervenção humana direta e de políticas de preservação digital para chegar num quadro de resolução (INNARELLI, 2011).

A organização dos acervos audiovisuais vai ser devidamente sinalizada, pois para existir uma relação efetiva entre acervos e usuários a informação precisa ser sistematizada para recuperação, e para a informação da documentação audiovisual cumprir tal objetivo se faz necessário encontrar com precisão no acervo a documentação desejada. Neste cenário é fundamental que existam representações bem definidas para lidar com os metadados, e profissionais da Ciência da Informação com técnica e sensibilidade para lidar com a organização de acervos deste gênero.

Outra questão relevante se concentra na relação entre Ciência da Informação com acervos audiovisuais. Pretende-se levantar de forma contextualizada a problemática enfrentada pelas três áreas de CI, no intuito de estabelecer articulações de possíveis planos a serem adotados e até mesmo executados na mesma sintonia pelas três áreas da CI. E a partir de uma padronização interdisciplinar poderá ser possível estabelecer um planejamento transdisciplinar.

Sendo assim, caracteriza como problema de pesquisa, o seguinte questionamento: como podemos oferecer uma padronização transdisciplinar para as políticas de preservação de acervos audiovisuais?

$\mathrm{O}$ objetivo geral desse trabalho pretende caracterizar os conceitos e definições sobre o acevo audiovisual relacionadas à preservação do acervo audiovisual a partir do estado da arte, no intuito de oferecer possibilidades para as políticas de preservação de acervos audiovisuais.

O acervo audiovisual é caracterizado por sua imensa diversidade, esta é uma das razões dele não ser tratado com a mesma singularidade pelas três áreas da CI, em comparação com outros tipos de documentação. Há certa dificuldade das Unidades de 


\section{SEMINÁRIO DE PESQUISA EM CIÊNCIAS HUMANAS - SEPECH \\ Humanidades, Estado e desafios didático-científicos \\ Londrina, 27 a 29 de julho de 2016}

Informação em organizar e fazer a manutenção dos acervos audiovisuais de forma adequada, principalmente por causa de sua natureza distinta, plural e transdisciplinar. Neste sentido existe a necessidade de fomentar mais diálogos, debates e pesquisas colaborativas entre a Biblioteconomia, a Museologia e a Arquivologia, pois a partir da cooperação entres estas três áreas da CI se tornarão viáveis estabelecer uma série de estratégias no intuito de criar regras fixas de padronização desta espécie de acervo.

A cooperação entre as três Marias é de suma relevância, pois o que está em jogo é o futuro da preservação dos suportes audiovisuais e cabe a Ciência da Informação fazer o tratamento desta documentação, adotando uma série de medidas padronizadas para posterior recuperação da informação, antes que os acervos se percam. Embora haja políticas de preservação de acervos audiovisuais de prestigiados órgãos internacionais e nacionais, em pleno ano de 2016, ainda não ocorreu uma série de medidas políticas que visam padronizar os acervos audiovisuais no âmbito da Ciência da Informação.

Trata-se de uma pesquisa exploratória de caráter qualitativo de cunho teórico que aborda os temas de: curadoria, curadoria digital, manutenção, organização e representação da informação. A análise exploratória e descritiva da literatura disponível sobre o tema proposto permitirá a construção de um conhecimento teórico sobre as atividades curatoriais que orientam as possibilidades de representação e organização da informação, que auxiliarão na compreensão do problema proposto e na construção dos resultados esperados.

O consenso interdisciplinar, a respeito das políticas de acervos audiovisuais, é de crucial importância na Ciência da Informação, pois fixar normas auxiliará outras áreas do conhecimento a tratar e cooperar com as políticas da Ciência da Informação. O presente projeto pretende contribuir nesta relevante discussão a respeito dos acervos audiovisuais.

\section{DOCUMENTAÇÃO AUDIOVISUAL E A PRESERVAÇÃO}

As especificidades que envolvem a documentação audiovisual se diferenciam da documentação do tipo textual em vários aspectos, como por exemplo, na pluralidade dos diversos tipos de conteúdos e formas, simultaneamente o registro audiovisual necessita de algum recurso tecnológico que cumpre uma função intermediária entre forma e usuário para poder ser contemplado. Esta é uma característica peculiar deste tipo de registro, pois o registro audiovisual necessita de alguma tecnologia intermediária para chegar até o destinatário final (BUARQUE, 2008), segundo Bethônico (2006) "as formas audiovisuais ficam associadas ao emprego de instrumentos da tecnologia moderna para sua produção e uso".

Dentro da pluralidade que abrangem tais características como suporte, conteúdo e até mesmo dispositivos tecnológicos deste tipo de registro, se constatam particularidades, singularidades bem específicas.

Segundo Oliveira (2011, p. 17) “[...] documentos audiovisuais são produzidos, armazenados, organizados, usados, transformados, ressignificados em função das mais variadas necessidades apresentadas pela sociedade".

Existe a necessidade cada vez mais frequente do diálogo entre diversas áreas do conhecimento em viabilizar estratégias eficazes com relação ao manuseio e a 


\title{
XI SEMINÁRIO DE PESQUISA EM CIÊNCIAS HUMANAS - SEPECH \\ Humanidades, Estado e desafios didático-científicos \\ Londrina, 27 a 29 de julho de 2016
}

preservação de acervos audiovisuais, seja numa biblioteca, numa emissora de televisão ou mesmo num centro de medicina. Sobretudo esta é uma das funções da alçada do cientista da informação, é de suma importância que estes profissionais participem ativamente dos diálogos que envolvam demais profissionais de outras áreas, e também que executem ativamente os procedimentos relativos ao manuseio e preservação de acervos audiovisuais.

\begin{abstract}
Alguns autores consideram o audiovisual como uma polifonia de linguagens, imagem, som musical, palavra e escrita. Avançando em tal linha de pensamento, o audiovisual deixa de representar apenas dois caminhos diferentes - o visual e o sonoro - de acesso ao conhecimento. Passa a ser visto como multidimensional e plurissensorial, integrando outros órgãos do sentido em formas sofisticadas de comunicação sensorial. (BETHÔNICO, 2006, p.60)
\end{abstract}

O acervo audiovisual paulatinamente foi ganhando espaço e importância conforme define Buarque (p. 02, 2008), "É, portanto, relativamente recente o reconhecimento, por parte de arquivistas e pesquisadores, dos documentos audiovisuais enquanto patrimônio cultural, os quais devem ser preservados e difundidos por seguidas gerações".

Com a crescente consciência da importância em preservar os acervos audiovisuais foram criadas, desenvolvidas e recomendadas técnicas de padronização. A digitalização deste material é uma ferramenta de vital importância para a sua sobrevivência. Porém somente digitalizar o material não assegura a eficácia de sua preservação, é imprescindível conservar o acervo analógico, e os dispositivos tecnológicos responsáveis pela criação e execução dos suportes, neste caso se faz necessário que as unidades de informação tenham em suas equipes profissionais, com competência para trabalhar tanto com acervo analógico e seus dispositivos, como também profissionais gabaritados em equipamentos da esfera digital (BUARQUE, 2008).

As duas mais importantes etapas no processo de preservação de suportes analógicos são: a digitalização e a conservação preventiva. Estas duas etapas se imiscuem e caminham juntas. Para ser possível manter uma preservação em longo prazo, a digitalização é o procedimento de melhor eficácia, a digitalização praticamente não altera os conteúdos do suporte analógico no momento da passagem para o sistema digital, os sistemas digitais possuem precisão matemática, e são armazenados em repositórios digitais, (BUARQUE, 2008).

Depender somente da digitalização, no processo de preservação, pode gerar danos irreparáveis, a ponto de se perder totalmente acervo. Neste sentido se faz necessário utilizar outras técnicas de preservação, mais precisamente a denominada Conservação Preventiva, esta é a técnica mais efetiva de materiais de acervos no estado analógico. Ao contrário das técnicas de restauração a conservação preventiva atua no ambiente que circunda o acervo e não se caracterizando por uma intervenção direta no objeto. De acordo com a definição de Buarque (2008, p.3) a Conservação Preventiva se caracteriza por:

A conservação preventiva estuda, controla e atua sobre cinco elementos principais, que nada mais são do que fatores ambientais: 


\section{SEMINÁRIO DE PESQUISA EM CIÊNCIAS HUMANAS - SEPECH \\ Humanidades, Estado e desafios didático-científicos \\ Londrina, 27 a 29 de julho de 2016}

água (mais especificamente umidade), temperatura, poeira, radiação ultravioleta e campos magnéticos. Além desses elementos, também atua em fatores de armazenamento e manuseio, uma vez que a maneira como um objeto é manuseado e acondicionado também é um forte condicionante para a sua expectativa de vida.

Os principais elementos que devem ser constantemente cuidados são: temperatura e umidade, o maior erro de muitas unidades de informação consiste em não acondicionar umidade e temperatura em perfeita sincronia, pensar na umidade sem pensar na temperatura e vice-versa também podem desencadear danos irreparáveis. Inclusive existem normas internacionais com relação à sincronia da umidade e temperatura, mais fáceis de serem aplicadas em países do hemisfério norte, no Brasil a medida aplicada de forma rigorosa pode gerar gastos expansivos.

No que tange a preservação de documentos digitais, é fundamental obter apetrechos que asseguram com eficácia a manutenção do acervo. A preservação prospectiva repara e restaura o suporte digital, dando prognósticos e diminuindo as ameaças das consequências inerentes, da mesma forma a preservação retrospectiva visa restaurar materiais degenerados. Arellano (2004) corrobora que os repositórios de dados digitais podem ser considerados importantes artifícios de preservação para armazenar suportes digitais, no contexto de proteção de sua inextinguibilidade. A preservação lógica busca na tecnologia formas atualizadas para introduzir novos dados de software e hardware que sustente firmemente seus respectivos bits, mantendo sua leitura eficiente, a preservação física de acervos audiovisuais continua sendo expressivo e fundamental, mesmo o seu armazenamento demonstrando a incessante necessidade migrar para novos materiais (disquete, fita VHS, CD-ROM, DVD etc.).

A constituição da Ciência da Informação se caracteriza por três áreas, conhecidas como 3 Marias: Arquivologia, Biblioteconomia e Museologia. Segundo Smit (1993, p.1) "[...] os documentos audiovisuais constituem um campo privilegiado de interface entre museologia, arquivística e biblioteconomia e documentação".

Embora estas três áreas da CI se complementem, gerando um consistente laço informacional, há algumas diferenças quando se trata de estratégias de organização dos seus respectivos acervos em cada Unidade de Informação.

A gestão dessa documentação, baseada exclusivamente em princípio operacionais e instrumentais não se mostra adequada para proporcionar um diálogo plural diante das necessidades almejadas pelos sujeitos. Quem busca informação audiovisual coloca em evidência a interferência de um referente que se manifesta de maneira própria e peculiar, muito diferente dos objetos presentes na informação textual-escrita. (OLIVEIRA, 2011, p. 02)

A problemática está relacionada aos acervos audiovisuais vai além das estratégias de tratamento, pois existe uma indeterminação terminológica, e sobre a definição exata do suporte audiovisual em si. A própria dificuldade em definir o material audiovisual desarticula em alguma medida, a tentativa de padronização estratégica em organizar os acervos audiovisuais na esfera das Unidades de Informação das três áreas que compõem a CI. Quando se trata de suporte audiovisual 


\section{SEMINÁRIO DE PESQUISA EM CIÊNCIAS HUMANAS - SEPECH \\ Humanidades, Estado e desafios didático-científicos \\ Londrina, 27 a 29 de julho de 2016}

não há entendimento quanto ao tipo de material e sua terminologia, várias denominações são utilizadas rotineiramente como sinônimos, é possível citar inúmeros exemplos: mídia (ou média) áudio-visual, materiais audiovisuais, materiais especiais, materiais não impressos, materiais não-bibliográficos, multimeios, AVM, $\mathrm{AV}$, non-book media e meios não-gráficos (BETHÔNICO, 2006).

Smit (p.1, 1993) afirma que os acervos audiovisuais são considerados terra de ninguém, justificados em parte pelo seu perfil transdisciplinar, ou seja, não existe uma delimitação precisa que encarrega qualquer uma das 3 Marias de tratar a documentação audiovisual como sendo dos seus respectivos âmbitos profissionais.

A organização do documento audiovisual constitui, de fato, um no man's land profissional, no qual várias profissões estão envolvidas, freqüentemente até por razões fortuitas, uma vez que os documentos audiovisuais podem iniciar sua trajetória como suporte ou sub-rotina de outra atividade que, esta sim, traz um nome definido (biblioteca, centro de documentação, museu, arquivo).

Outro fator preponderante a ser registrado é a falta de bibliografia específica em torno conceito no man's land profissional, salienta Smit (1993). Um exemplo que demonstra de forma clara o contexto da oscilação terminológica das Três Marias é encontrado no Arquivo Nacional do Rio de Janeiro, o qual agrega um universo de suportes sonoros numa "Divisão de Documentação Audiovisual", este setor procura organizar e descrever os suportes sonoros, levantando questões existentes dentro da AACR (Anglo-American Cataloguing Rules) e da ISBD (International Standard Bibliographic Description). O Arquivo Nacional descreve um punhado de sugestões, nos quais o título acaba girando em torno da terminologia arquivístiva: "manual de procedimentos para descrição de arquivos sonoros" (SMIT, 1993 apud JAEGGER e SILVA, 1985).

Cada área de CI trata da documentação audiovisual de uma maneira peculiar, e agem de forma corporativista, crendo que seus respectivos métodos são mais eficazes em comparação com as demais, além de excluírem qualquer alternativa empregada pelas outras Marias. Smit (1993) enxerga que não há um sistema de cooperação e intercâmbio entre as áreas de Biblioteconomia, Museologia e Arquivologia com relação à documentação audiovisual, e independente do espaço ou lugar que tratam de acervos audiovisuais, as preocupações metodológicas das Unidades de Informação das distintas áreas são as mesmas.

O profissional da área de CI não foi formado para trabalhar com este tipo de suporte, de forma genérica, estes profissionais se especializaram em objetos, livros, documentos, desta forma é comum por parte dos profissionais em CI intitularem, em suas Unidades de Informação, o espaço reservado aos acervos audiovisuais como sendo 'outro', ou algum nome do gênero. 'O material audiovisual é um território, o livro é outro, e, já está estabelecido na mente do usuário: a informação mais confiável para aplicações profissionais e acadêmicas está na biblioteca, na forma de livro ou periódico" (BETHÔNICO, 2006 p.68).

É preciso ter uma sensibilidade aguçada para tratar e organizar a descrição da documentação audiovisual, sensibilidade encontrada em outras profissões que fogem 


\section{SEMINÁRIO DE PESQUISA EM CIÊNCIAS HUMANAS - SEPECH \\ Humanidades, Estado e desafios didático-científicos \\ Londrina, 27 a 29 de julho de 2016}

do espectro da CI, quase sempre esta sensibilidade está longe da alçada dos profissionais das 3 Marias (SMIT, 1993).

Este contexto de indefinição terminológica no universo dos acervos audiovisuais em CI encontra-se muito além das fronteiras brasileiras, é uma indefinição de caráter internacional, mais especificamente pela International Association of Sound Archives (IASA), o nome da entidade traduzindo para o português significa Associação Internacional de Arquivos de Som e Audiovisual, sinaliza uma miscelânea terminológica que consagra estrutura no man's land da organização documental em audiovisual pela CI. O livro "Sound Archives: a guide to their establishment and development", editado pela IASA, revela um apanhado de diferentes nomenclaturas heterogêneas com relação aos suportes de áudios (SMIT, 1993 apud LANCE, 1983).

O conflito terminológico dificulta a construção de uma padronização transdisciplinar no tratamento dos acervos audiovisuais, independente do tipo de Unidade de Informação que ele esteja inserido. Representar, organizar e fazer a manutenção requer habilidade técnica e sensibilidade, a consciência do cientista da informação precisa existir institucionalmente, por meio de encontros, no intuito de discutir a padronização do audiovisual e também através da implementação de disciplinas voltadas a este tema na grade curricular dos cursos de CI. Conforme a informação eleva seu nível de complexidade, aumentam os conflitos sobre a segurança de representar e organizar o acervo, acontece uma carência de conhecimento e de profissionais neste ramo para enfrentar aspectos relacionados à comunicação e a expressão de suportes audiovisuais, em funções consideradas comuns nas atividades da Ciência da Informação, como por exemplo: seleção, aquisição, preservação, catalogação, uso e restauração (BETHÔNICO,2006, p70).

É imprescindível romper as barreiras existentes entre Ciência da Informação e acervos audiovisuais, o futuro da preservação e disseminação deste tipo de suporte depende de uma transdisciplinar política de manutenção, as quais envolvem as três áreas da Ciência da Informação, e uma gama de outras áreas que se relacionam direta ou indiretamente, tanto com a própria Ciência da Informação, assim como o suporte e consequentemente o acervo audiovisual. Pela estrutura transdisciplinar dos materiais audiovisuais, há necessidade de um amplo diálogo interno entre os profissionais de CI, além da construção de um debate plural e democrático entre CI e as áreas de cinema, jornalismo, pedagogia, rádio \& TV etc. (OLIVEIRA, 2011).

A maior parte dos acervos audiovisuais está sendo digitalizada ou são digitais, e seus acervos são inseridos em bancos de dados em diversos tipos de repositórios. Nos bancos de dados toda a documentação digital do audiovisual ganha espaços em proporções infinitamente maiores em relação ao físico, a dinâmica versátil de se produzir mais materiais numa rapidez cada vez mais intensa possuindo estocagens gigantescas, gera um colossal fluxo de disseminação da informação, automaticamente causando impacto direto na relação entre Ciência Informação e acervos audiovisuais. A atual Revolução Tecnológica se baseia em aplicações de conhecimentos e dispositivos de processamento e comunicação da informação, gerando uma acumulação entre usabilidade e inovação (CASTELLS, 1999). 


\section{SEMINÁRIO DE PESQUISA EM CIÊNCIAS HUMANAS - SEPECH \\ Humanidades, Estado e desafios didático-científicos \\ Londrina, 27 a 29 de julho de 2016}

\section{CONSIDERAÇÕES PARCIAIS}

O trabalho está em desenvolvimento, por essa razão considera-se que a informação, conhecimento e memória podem desaparecer sem deixar rastro de registros, neste sentido é de suma importância um debate aprofundado a respeito da organização e preservação do acervo audiovisual entre as Três Marias da CI, se torna necessário encontrar possibilidades que se aproximem de um consenso e uma consequente padronização. Para o profissional de CI, este é um desafio urgente, enquanto não houver tratamento adequado aos acervos audiovisuais parte do conhecimento e da memória coletiva da humanidade paulatinamente vai se deteriorando, se diluindo, se perdendo.

Assim, como a pluralidade existente no âmbito do singular universo dos acervos audiovisuais, seja pelo formato, pelo conteúdo ou mesmo pelo tipo de dispositivo tecnológico que se faz necessário, é possível verificar o caráter transdisciplinar da utilização dos acervos audiovisuais como patrimônio cultural, pois a universalidade deste tipo de acervo é contemplada por diversas áreas do conhecimento.

\section{REFERÊNCIAS}

ARELLANO, Miguel Angel. Preservação de documentos digitais. Ciência da Informação, Brasília, v. 33, n. 2, p.15-27, maio/ago. 2004. Quadrimestral. Disponível em: <http:/www.scielo.br/pdf/ci/v33n2/a02v33n2.pdf >. Acesso em: 28 mar. 2016.

BETHÔNICO, Jalver. Signos audiovisuais e Ciência da Informação: uma avaliação. In: ENC. BIBLI: R. ELETR. BIBLIOTECON. CI. INF, 2., 2006, Florianópolis. Encontros Bibli: revista eletrônica de biblioteconomia e ciência da Informação.Florianópolis: Universidade Federal de Santa Catarina, 2006. p. 58 - 78. Disponível em: <http://docplayer.com.br/1430163-Signos-audiovisuais-e-ciencia-dainformacao-uma-avaliacao-audiovisual-signs-and-information-science-anevaluation.html>. Acesso em: 28 mar. 2016.

BUARQUE, Marco Dreer. Estratégias de preservação de longo prazo em acervos sonoros e audiovisuais. In: ENCONTRO NACIONAL DE HISTÓRIA ORAL, 9., 2008, São Leopoldo, Rs. Associação Brasileira de História Oral. São Leopoldo, Rs: Anais ... Rio de Janeiro, 2008. p. 1 - 9. Disponível em:

$<$ http://cpdoc.fgv.br/producao_intelectual/arq/1718.pdf $>$. Acesso em: 28 mar. 2016.

CASTELLS, Manuel. A sociedade em rede. 9. ed. São Paulo: Paz e Terra, 2006. 1 v. A Era da Informação: Economia, Sociedade e Cultura.

INNARELLI, Humberto Celeste. Preservação digital: a influência da gestão dos documentos digitais na preservação da informação e da cultura. Revista Digital de Biblioteconomia e Ciência da Informação, Campinas, v. 8, n. 2, p.72-87, jan./jun. 2011. Semestral. Disponível em: 


\section{SEMINÁRIO DE PESQUISA EM CIÊNCIAS HUMANAS - SEPECH \\ Humanidades, Estado e desafios didático-científicos \\ Londrina, 27 a 29 de julho de 2016}

$<$ http://www.sbu.unicamp.br/seer/ojs/index.php/rbci/article/view/487/330>. Acesso em: 28 mar. 2016.

OLIVEIRA, Roni Santos. Audiovisual \& Informação: Princípios elementares. São Paulo, 2011. 24 p.

SOTERO, Alfredo. Patrimônio audiovisual é memória da humanidade.

Universidade Católica de Pernambuco, 2013. Disponível em:

$<$ http://www.unicap.br/graduacao/rrpp/?p=258>. Acesso em: 28 mar. 2016.

SMIT, Johanna W. O documento audiovisual ou a proximidade entre as 3 Marias. Texto publicado originalmente na Revista Brasileira de Biblioteconomia e

Documentação, 26 (1/2): 81-85, jan/jun.1993. Disponível em:

$<$ http://www.brapci.ufpr.br/documento.php?dd0 $=0000002163 \& d d 1=3 \mathrm{e} 67 \mathrm{~b}>$ Acesso em 28 mar. 2016. 